\title{
Diálogos entre enunciação e ensino de língua estrangeira
}

DOI: http://dx.doi.org/10.21165/el.v50i1.2971

\section{João Daniel Passarelli França' \\ Marília Blundi Onofre ${ }^{2}$}

\section{Resumo}

Este trabalho se insere no quadro da Teoria das Operações Predicativas e Enunciativas e visa avaliar a possibilidade de a enunciação contribuir para o ensino de língua estrangeira. Confrontamos duas metodologias de ensino, uma, instrumental, reconhecidamente presente no ensino de línguas que, grosso modo, privilegia o ensino da forma sobre o sentido; e outra, interacional/dialógica, proposta defendida aqui como um caminho a ser aplicado ao ensino por meio da enunciação. Para tanto estudamos os verbos frasais da língua inglesa, que constituem uma questão problemática por serem estruturas absolutamente típicas deste idioma, dotadas de características estranhas a falantes não nativos, o que os tornam um grande desafio didático. Para embasar nossa discussão, levantamos algumas questões acerca das abordagens tradicionais presentes em livros didáticos de língua inglesa, bem como sugerimos a aplicação de práticas enunciativas como forma de reflexão sobre a língua. Para desenvolver nossas análises, empregamos como exemplo uma manchete do jornal The New York Times, ocorrências em dicionários, entre outras fontes.

Palavras-chave: Teoria das Operações Predicativas e Enunciativas; verbos frasais; ensino de língua estrangeira; atividade epilinguística; noção.

\footnotetext{
1 Universidade Federal de São Carlos (UFSCar), São Carlos, São Paulo, Brasil; jdanielpf33@hotmail.com; https://orcid.org/0000-0002-3778-4019

2 Universidade Federal de São Carlos (UFSCar), São Carlos, São Paulo, Brasil; blundi@uol.com.br; https://orcid.org/0000-0002-7075-310X
} 


\title{
Dialogues between enunciation and foreign language teaching
}

\begin{abstract}
This work lies in the field of the Theory of Predicative and Enunciative Operations and aims to assess the potential contribution of enunciation to the teaching of foreign languages. We confront two teaching methodologies, one, instrumental, known to be dominant in the teaching of foreign languages, which, roughly speaking, privileges the teaching of form over meaning, and another one, interactional/dialogical, a proposal defended here as theoretical support for teachers who seek alternatives to the most traditional approaches to language teaching. Therefore, we chose the English phrasal verbs as the topic to illustrate this discussion since these structures are typical of the English language, containing characteristics that are extremely unfamiliar for non-native speakers, which makes them a didactic challenge. Our corpus of phrasal verbs is mostly extracted from dictionaries and a headline from The New York Times.
\end{abstract}

Keywords: Theory of Predicative and Enunciative Operations; phrasal verbs; foreign language teaching; wpilinguistic activity; notion.

\section{Introdução}

Dentre os motivos que nos levaram a realizar este trabalho, destacamos dois como sendo fundamentais: primeiramente, a observação de que as teorias enunciativas podem contribuir com o ensino de língua estrangeira (LE). Apesar da forte presença do construtivismo de Piaget (teoria que dialoga com a enunciação proposta por Antoine Culioli (1990) na educação brasileira, empiricamente, observamos que poucas práticas das aulas de LE são realmente influenciadas por suas ideias ${ }^{3}$. Este fato sempre nos causou uma grande inquietação. Em segundo lugar, em nosso dia a dia como professor de língua inglesa, observamos uma grande dificuldade no ensino-aprendizagem do conteúdo gramatical identificado como Verbos Frasais (VFs), o que nos levou a questionar a forma como estas marcas são abordadas. Dada a complexidade dos VFs, questão já reconhecida no ensino de língua inglesa, e, dado o seu alto grau de ocorrência, os escolhemos como objeto de nossa pesquisa no intuito de jogarmos um pouco mais de luz sobre este tópico.

Trabalhamos com a hipótese de que as dificuldades dos professores e alunos frente a esse conteúdo têm relação direta com a forma como se dá o ensino de línguas estrangeiras na maioria das escolas brasileiras, pautado sob o que Rezende (2008) classifica como

3 Os estudos que desenvolvemos sobre o ensino de LE, bem como nossa prática de ensino de língua inglesa amparam nossas afirmações. Apoiamo-nos, sobretudo, em Rezende (2008) e Marchena e Hulstjin (1989). 
uma concepção instrumental de ensino de línguas. Essa abordagem recebe aqui este nome por abordar a Língua Estrangeira (LE) como um instrumento do qual o aluno fará uso nas situações para as quais está estudando a língua-alvo (LA). Assim, se a finalidade do aluno for viajar para o país onde se fala a LA, seu curso vai consistir de palavras, frases e estruturas que ele provavelmente terá de usar durante sua estadia naquele país. Se a finalidade do aluno for prestar um exame de proficiência para uma pós-graduação, seu professor irá lhe passar textos específicos da área para a qual ele está prestando a prova, e assim por diante. Nesse sentido, privilegiam-se as formas linguísticas e suas funções sociais, e a aquisição linguística é vista como resultante de fragmentos das possíveis formas de competências discursivas, rompendo-se, assim, a articulação entre a linguagem e as línguas.

Embora a função comunicativa da língua tenha importância inegável para a vida do aluno, essa concepção instrumental de ensino apresenta, a nosso ver, algumas incongruências, especialmente, quanto à abordagem gramatical, em geral, trabalhada de modo desarticulado ao texto. Além deste, existem outros problemas como:

- escolha arbitrária dos itens léxico-gramaticais que são ensinados para o aluno. Muitos Livros Didáticos (LDs) ${ }^{4}$ ensinam alguns verbos e preposições e ignoram vários outros, que ocorrem com tanta ou mais frequência do que os abordados. Ensina-se que a preposição on, por exemplo, significa sobre/em cima de, como em The cat is on the couch (O gato está em cima do sofá). Porém, existem vários outros sentidos de on, igualmente frequentes, que são ignorados pelos LDs, o que limita consideravelmente a capacidade do aluno de usar esta preposição;

- ensino baseado em exercícios prescritivistas, prevalecendo o estudo das classes de palavras e das funções sintáticas, em detrimento da contextualização. 0 ensino, nessa perspectiva, despreza a reflexão e a produção do aluno;

- ideia padronizada do que seria "útil" para o aluno, como se todos aprendessem com os mesmos objetivos. Como observa Rezende (2008), nem todos os alunos estudam inglês pelos mesmos motivos, nem todos possuem os mesmos objetivos, assim esse ensino voltado para o "mercado de trabalho" torna-se desmotivante para eles.

Finalmente, é importante lembrar que VFs são estruturas típicas de línguas anglo-saxãs, possuindo, portanto, peculiaridades que os tornam de difícil assimilação para não nativos. Voltaremos a esta questão mais adiante.

4 Os livros didáticos analisados estão indicados à frente. No entanto, nossa afirmação se faz a partir de nossa larga experiência como professor de Língua Estrangeira e como usuário de livro didático. 
Usando como referencial teórico a Teoria das Operações Predicativas e Enunciativas (TOPE), quadro teórico proposto por Antoine Culioli (1990), esperamos provocar reflexões que contribuam para as práticas didáticas acerca das questões gramaticais apontadas, de modo que estas sejam abordadas em articulação com o exercício de produção textual.

Iniciamos nosso artigo por uma breve apresentação da TOPE e seus conceitos mais pertinentes para nosso trabalho. Na sequência, enfocamos os verbos frasais do inglês e o modo como estes são abordados por duas populares séries de livros didáticos. Apresentamos a análise de um enunciado contendo um VF para demonstrar as operações enunciativas da qual falamos na primeira seção. Finalmente, com base na análise do exemplo, discutimos algumas questões didáticas e apresentamos nossas considerações finais.

\section{A Teoria das Operações Predicativas e Enunciativas (TOPE) de Antoine Culioli - o conceito de linguagem}

A TOPE é uma teoria enunciativa de autoria do linguista francês Antoine Culioli (1990) que surgiu na esteira das ideias de Benveniste (1989) na medida em que ambos autores dão atenção especial ao que chamam de "marcadores" enunciativos, bem como ao que concebem como enunciado. Porém, como explica Vogüé (2011), tais autores distinguemse pela concepção que têm de enunciação. Enquanto para Benveniste a enunciação é um ato de apropriação da língua pelo sujeito, para Culioli trata-se de um processo que se recupera por meio do enunciado. Nesse sentido, a TOPE propõe a elaboração de um sistema de representação metalinguístico pelo linguista, que, para tal, deverá possuir uma intuição extremamente refinada. Para Culioli (2000), a linguagem é uma atividade complexa de significação, dado que se caracteriza por ser estável e, ao mesmo tempo, deformável por meio do agenciamento de formas linguísticas. Essas representações podem ser acessadas pelo linguista apenas na sua manifestação, por meio de textos orais e escritos, que the permitem "[...] apreender a atividade de linguagem através da diversidade das línguas naturais" (CULIOLI, 2000, p. 57). Quando fala em "atividade de linguagem", o autor está se referindo à produção e reconhecimento de formas. Para o estudo de tais formas, o linguista depende dos textos, uma vez que é neles que as línguas estão presentes.

A partir da célebre metáfora saussuriana do jogo de xadrez, podemos dizer que, grosso modo, o ensino tradicional, pautado pela instrumentalidade, tem enfocado as regras do jogo (a langue) ao passo que nossa proposta, de cunho enunciativo, enfoca os jogadores suas intenções e construções mentais, as quais são recuperadas a partir da observação criteriosa das posições das peças (agenciamento dos marcadores). Esta atividade linguístico-cognitiva é chamada na TOPE de atividade epilinguística. Falaremos sobre ela a seguir. 


\section{Atividade epilinguística}

Culioli (1990) define a atividade epilinguística (AE) como a atividade metalinguística nãoconsciente, anterior à materialização linguística. É um trabalho invisível do sujeito para a construção da significação e, nesse sentido, consiste em uma organização primária da enunciação. É um esforço mental para atingir o equilíbrio entre o eu e o outro (REZENDE, 2008), fundamentado pela instanciação dialógica. Essa metalinguagem inconscienteativa a relação entre três operações de linguagem, quais sejam: a operação de representação, de referenciação e de regulação.

\section{A representação}

Segundo Culioli (1999), esta operação possui três níveis. O primeiro, de ordem afetiva e cognitiva, ligado às representações mentais dos objetos, do mundo e da cultura. O autor explica, na mesma obra, que essas propriedades físico-culturais vão dar origem às noções. Estas são inacessíveis, porém, podem ser apreendidas através dos textos. O segundo nível engloba o arranjo de marcadores, as regras de boa formação. Os marcadores nos dão pistas das operações mentais. O último nível, por sua vez, é metalinguístico, porém, uma metalinguagem inconsciente, que envolve a reflexão do sujeito sobre sua experiência com uma ou mais línguas. Podemos dizer que a representação é totalmente centrada no aspecto afetivo e cognitivo do sujeito, seu mundo psíquico e suas elaborações culturais. A representação é, acima de tudo, sensorial. Ocorre antes do surgimento das marcas linguísticas.

Grosso modo, a representação se refere a todas as intuições e reações sensoriais que o sujeito tem em relação a uma marca linguística vista ou ouvida. É um raciocínio linguístico que ocorre antes do raciocínio consciente.

\section{A referenciação}

A referenciação é intrínseca à operação anterior, a representação. Referenciar, segundo Culioli (1999), significa localizar as representações. Neste nível, o sujeito toma consciência do outro, por conseguinte, descentraliza-se. Se antes estava voltado para seu próprio mundo psíquico, agora ele se volta para seu interlocutor e para o mundo. A referenciação é o momento em que surge o material linguístico. Em suma, nesta operação, vêm à mente do sujeito palavras, marcas e arranjos linguísticos.

\section{A regulação}

Regular implica buscar o equilíbrio na relação dialógica entre os significados construídos. Neste processo, o sujeito volta a centralizar-se. Neste processo de montagem e desmontagem de significados, os sujeitos da interação são, ao mesmo tempo, emissores 
e receptores tendo em vista que ambos dão significados às palavras e textos. Esta interação é fundamental para a construção de significação.

Em sua essência, a regulação consiste de ajustes entre os sujeitos que participam da enunciação, do esforço que eles fazem para construir o sentido de sua interação. Observemos um exemplo, de nossa própria autoria:

- Você não entregou o bilhete para o André?

- Entreguei sim!

- Ele disse que não recebeu...

- Como não? Deixei na mesa dele ontem.

- Espera aí. Pra qual André você entregou?

- Pro da contabilidade...

- Não...era pro outro André, aquele da secretaria...

- Ah, tá ...

Os sujeitos possuem uma representação diferente para /André/. Logo, a referência que encontram para esta marca também é diferente. Consequentemente, são necessários ajustes, por meio de marcas como "qual André", "o da contabilidade", "da secretaria", entre outras, para que os sujeitos possam construir um sentido semelhante para /André/. Grosso modo, é isso que a TOPE chama de regulação.

As operações de representação, referenciação e regulação entram em cena no momento em que o aluno traduz um enunciado da LE para sua Língua Materna (LM), na medida em que a construção do sentido do enunciado da LE ativará suas reações sensoriais ao enunciado proposto (representação), suas associações do enunciado com o mundo (referenciação) e o ajuste entre suas representações e as de seu interlocutor (regulação). Falaremos mais sobre tradução à frente.

\section{Noção e domínio nocional}

A noção é um sistema complexo de representação que organiza propriedades físicoculturais de natureza cognitiva. Ela existe antes que as palavras se tornem categorias e é geradora de unidades lexicais. A noção é geralmente representada entre barras, por exemplo, /raposa/; ela é um predicado em potencial ("ser uma raposa", "ter a propriedade de ser uma raposa"). Este predicado é definido apenas em intensão. As noções possuem um certo grau de estabilidade, sem o qual não haveria comunicação, porém, não são 
fixadas de modo definitivo. Pelo contrário, são dinâmicas e variam de um indivíduo para outro e de uma situação para outra. É apenas através de suas ocorrências que uma noção pode ser apreendida.

Trata-se de um dos conceitos mais complexos do modelo culioliano. O autor define noção como um conjunto de eventos que possuem a mesma propriedade. Por exemplo, a propriedade "ser raposa" refere-se a uma ocorrência específica e, ao mesmo tempo, a qualquer ocorrência de "raposa." Então, para definir o que é "ser raposa" é preciso isolar um certo número de propriedades que estão de acordo com tudo aquilo que realmente merece o nome "raposa". Trata-se de um processo de abstração que põe em jogo a representação particular de "raposa" e a representação coletiva desta noção - aquilo que as outras pessoas concebem como raposa. Podemos dizer que, grosso modo, a noção envolve tudo que constitui algo. Assim, a noção /ser raposa/ engloba conceitos como animal, quadrúpede, mamífero, astuto, entre outros.

Já o domínio nocional (DN), segundo Culioli (1985), origina-se da noção e permite que o enunciador estruture as ocorrências associadas a uma dada noção específica. O DN constitui-se em torno de uma ocorrência que serve como referência. Esta ocorrência recebe o nome de centro organizador e está dividida em três áreas:

O interior do domínio nocional, marcado por relações de identificação com o centro organizador, quando as ocorrências possuem todos os traços que constituem a noção. Ex.: "um livro de verdade" (não uma brochura ou um catálogo). Algo que possui tudo aquilo que é necessário para "ser livro";

O exterior do domínio nocional engloba as ocorrências que expressam desconexão, separação do centro organizador. Ex.: "não é um livro mesmo" (não possui nenhum dos traços necessários para "ser livro").

A última área é a fronteira do domínio nocional. As ocorrências desta área possuem traços tanto do interior quanto do exterior do centro organizador. Ex.: "Não são realmente cachorros" (podem possuir alguns traços de "ser cachorro", mas não todos os traços necessários para serem realmente cachorros).

\section{A tradução na ótica culioliana}

O conceito de tradução dentro da TOPE é importante para nosso trabalho, uma vez que a construção de sentido do aluno de LE envolve traduzir (interpretar) os enunciados da língua-alvo. Na perspectiva culioliana, a Atividade Epilinguística, a Noção e o Domínio Nocional, vistos anteriormente, terão um papel fundamental para o processo de tradução. 
Se a linguagem resulta da Atividade Epilinguística, o conceito de tradução "fiel" e "objetiva" cai por terra porque as representações mentais de um signo lido ou ouvido são como impressões digitais - únicas para cada indivíduo. As experiências que constituem as representações mentais do tradutor são diferentes daquelas do autor do texto original. Por mais que o tradutor (o aluno, em nosso caso) tente ser "imparcial" ou "isento", essa experiência pessoal se fará presente em sua tradução. A metalinguagem inconsciente do processo de tradução é irrepetível, é exclusiva de cada tradutor e toda tradução sempre passa pelo filtro subjetivo do tradutor (BIASOTTO-HOLMO, 2010). Além disso, o modelo culioliano é marcado pelo conceito de indeterminação da linguagem. Isso significa que as marcas léxico-gramaticais não possuem um sentido fixo e imutável que pode ser simplesmente "transportado" de um idioma para outro.

Por outro lado, o fato de não existir tradução absolutamente fiel e objetiva não implica dizer que o aluno tenha liberdade plena. O aluno/tradutor deve buscar o máximo possível de semelhança ou equivalência semântica com o texto original (BIASOTTO-HOLMO, 2010).

Neste processo, além da Atividade Epilinguística, a tradução do aluno vai apoiar-se na Noção e Domínio Nocional porque a interpretação do sentido do enunciado original passa invariavelmente pelas propriedades físico-culturais daquele termo, as quais definem tudo que ele pode e não pode ser. Assim, traduzir um termo do inglês nada mais é do que distinguir entre o que se identifica com o que vimos como Centro Organizador de uma noção (suas propriedades típicas) e o que não se identifica com o centro (seu exterior, aquilo que não tem a ver com ele). Vejamos um exemplo:

I held back during the meeting because I knew my opinions were too controversial. (PASSARELLI, 2020, p. 117).

(Eu me contive na reunião porque sabia que minhas opiniões eram polêmicas demais)

O VF é formado pelas noções /hold/ e /back/. Embora hold possua várias acepções, podemos dizer que seu centro organizador, seu sentido dominante, é segurar. Já no interior da noção back temos atrás/para trás. Ao acessar estas duas ideias centrais, o aluno construirá algo como "segurar para trás". Como em português não costumamos dizer "Eu me segurei para trás", o aluno deverá usar sua metalinguagem inconsciente (raciocínio linguístico) para encontrar uma forma mais apropriada como contive (ele poderia, ainda, optar por ignorar a preposição back e traduzir simplesmente como "Eu me segurei", porém esta construção pode ser informal demais para algumas situações enunciativas). Obviamente, as marcas cotextuais também contribuirão para a construção do sentido. O fato de o falante achar suas opiniões "polêmicas demais" sugere que ele está se contendo. 
Por outro lado, para produzir na LE, o aluno fará o mesmo processo, só que desta vez do português para o inglês. Ou seja, para transformar contive em held back ele deverá associar conter-se a ideias como se segurar (hold), não progredir, não ir para frente, ir na direção oposta de frente (back), entre outras elaborações mentais. Este raciocínio metalinguístico, que é inconsciente, eventualmente o aproximará de hold back.

Como podemos ver, então, há uma intrínseca relação entre Aprendizagem de LE, Tradução, Atividade Epilinguística, Noção e Domínio Nocional. Produzir e interpretar enunciados na Língua Alvo (LA) implica traduzir neste idioma, que por sua vez implica raciocinar inconscientemente sobre essa LA. Esse raciocínio inconsciente, que diz respeito à atividade epilinguística (AE), por sua vez, se baseia nas propriedades físico-culturais das marcas a serem traduzidas. Estudaremos mais um exemplo destas relações na seção final deste artigo.

\section{Os verbos frasais da língua inglesa - conceituação, história e particularidades}

Seja devido à desaprovação de gramáticos ultrapassados, ou ao fato de que seu uso é, na maioria das vezes, mais coloquial do que literário, persiste ainda um certo preconceito contra verbos frasais e muitos escritores os evitam talvez até inconscientemente. Porém, "os VFs possuem um caráter genuinamente inglês, eles acrescentam imensamente à riqueza de nosso vocabulário... e talvez seja em coloquialismos deste tipo... que chegamos mais próximo ao coração idiomático da língua inglesa." (LOGAN PEARSALL SMITH "English Idioms", 1923, p. 58-59, tradução e grifos nossos). ${ }^{5}$

De acordo com Wild (2010), um verbo frasal é um lexema formado por um verbo mais uma preposição. Ao todo, temos três possibilidades de construção:

1. Verbo frasal intransitivo: / give up. (Eu desisto)

2. Verbo frasal transitivo com objeto direto nominal: Billy took his shirt off / Billy took off his shirt (Billy tirou a camisa)

5 No original: "Whether due to the disapproval of old - fashioned grammarians, or to the fact that their use is, for the most part, more colloquial than literary, there still persists a certain prejudice against phrasal verbs, and many writers half - consciously avoid them... But they are genuinely English in their character; they add immensely to the richness of our vocabulary... and it is perhaps in colloquialisms of this kind... that we come nearest to the idiomatic heart of the English language". 
3. Verbo frasal transitivo com objeto direto pronominal: She let me down / * She let down me (Ela me decepcionou)

( ${ }^{*}$ construção impossível)

O termo verbo frasal foi cunhado por Logan Pearsall Smith em 1923, embora já haja registros de VFs como eat up em uma tradução da bíblia de 1535 (WILD, 2010). Estas marcas sempre foram de difícil assimilação para falantes de línguas não-anglicanas, como o português e todas as outras línguas românicas. Segundo estudo da Universidade de Amsterdam (MARCHENA; HULSTJIN, 1989), os VFs apresentam dois grandes desafios para alunos de línguas não-anglicanas. O primeiro e maior obstáculo está na grande mudança semântica causada pelo acréscimo da preposição. Vejamos no Quadro 1:

Quadro 1. Verbo Isolado e Frasal

\begin{tabular}{|l|l|l|}
\hline Verbo Isolado & Verbo Frasal & Exemplo \\
\hline Call = chamar & Call off = cancelar & They called off the meeting (Eles cancelaram a reunião) \\
\hline
\end{tabular}

Fonte: Estudo da Universidade de Amsterdam (MARCHENA; HULSTJIN, 1989)

Para um aluno brasileiro, "chamar" e "cancelar" são ideias completamente distintas. Ele não entende, portanto, como elas podem ser representadas pelo mesmo verbo (call). De modo geral, é muito difícil para os alunos estabelecerem uma relação entre as duas ideias.

Além desta dificuldade, Marchena e Hulstjin (1989) também apontam outro problema: o uso de duas ou três palavras para expressar uma única ação, fato que também é muito incomum em grande parte das línguas não-anglicanas, como podemos ver na comparação entre o inglês e o português no Quadro 2:

Quadro 2. Uso de duas ou três palavras para expressar uma única ação

\begin{tabular}{|l|l|l|}
\hline Ação & Verbo Português Brasileiro & Verbo Frasal \\
\hline Educar filhos & Criar & Bring up \\
\hline $\begin{array}{l}\text { Chegar a alguém ou algo que está em um nível } \\
\text { mais avançado }\end{array}$ & Alcançar & Catch up with \\
\hline
\end{tabular}

Fonte: Estudo da Universidade de Amsterdam (MARCHENA; HULSTJIN, 1989)

Outro entrave cognitivo dos VFs é que eles não podem ser traduzidos palavra a palavra. Se traduzirmos call off literalmente teremos algo como "chamar desligado". Além disso, o fato de haver formas verbais mais latinizadas como opção aos VFs faz com que os alunos se acomodem com estas marcas e deixem de aprender os VFs. Ou seja, ao invés 
de aprender go on, o aluno contenta-se em conhecer continue. Porém, embora continue satisfaça uma necessidade comunicativa imediata do aluno, a longo prazo este aluno sentirá falta do conhecimento de VFs porque a comunicação em inglês se baseia mais nas formas anglo-saxãs do que nas latinizadas.

Para Wild (2010), os VFs são mais "vivos" para os falantes nativos do que as formas de apenas uma palavra, uma vez que o sentido original destas muitas vezes já se perdeu com o tempo. Tomemos como exemplo os verbos raise e bring up. Ambos têm o sentido de criar/educar filhos. Porém, enquanto raise não lembra em nada o ato de educar alguém, bring up (trazer para cima) faz uma menção, uma descrição desta ação - criar alguém envolve ajudá-lo a "crescer", colocar-se "em pé" no mundo, entre outras acepções. Ou seja, o VF, de certa forma, é um desenho da ação, do "movimento para cima" (up) que faz parte do crescimento. Por isso, é mais vivo para o falante nativo. Ao evitar o VF, o aprendiz tira um pouco da "vida" de seu discurso, torna seu discurso um pouco mais "burocrático".

Os VFs são construções altamente frequentes da língua inglesa. Segundo o British National Corpus (2000), eles ocorrem uma vez a cada quarenta palavras faladas e duas vezes por página escrita. Este alto grau de incidência reforça a importância de se ensinarem estas marcas, demonstra que elas não podem ser simplesmente ignoradas. Além disso, embora haja opções para substituir um VF em um enunciado, existem diferenças, muitas vezes significativas, entre uma ou outra marca. Nenhum verbo conserva exatamente o mesmo sentido do VF que substitui, uma vez que não existe paráfrase perfeita, ou seja, é impossível dizer "a mesma coisa" com palavras diferentes (FUCHS, 1982). Ademais, do ponto de vista didático, não é recomendável deixar o aluno se acomodar com as formas verbais que Ihe são mais familiares. É preciso estimulá-lo a aprender novas estruturas, por mais complexas que elas sejam.

Em suma, VFs são um importante componente da língua inglesa e evitá-los resulta no empobrecimento do ensino deste idioma. É preocupante, portanto, observar a baixa frequência destas marcas na produção de alunos não nativos.

\section{Verbos frasais e preposições nos livros didáticos}

O livro didático tem uma presença determinante na sala de aula, porque muitas das práticas didáticas são determinadas por ele. Seu papel é tão importante que muitos costumam, equivocadamente, chamá-lo de método, como se o livro fosse o próprio curso. Por este motivo, neste item vamos falar um pouco sobre a forma como VFs e preposições são abordados em duas das séries mais populares do mundo - American English File (AEF) (2014, $2^{a}$ edição) e Interchange (IC) (2017, $5^{\text {a }}$ edição). Ambas as séries são compostas de quatro níveis, portanto, analisamos, ao todo, oito livros. 
Em ambas as séries, os verbos frasais são apresentados por meio de listas que variam em média de cinco a dez novos verbos. Os significados correspondentes são dados em inglês. No IC, o significado em inglês é dado ao aluno, ao passo que no AEF, geralmente há um exercício de associação ou preenchimento de lacunas. Não encontramos forma alguma de contextualização dos VFs nos livros analisados. Ainda sobre a apresentação do tópico, observamos uma certa confusão na hora de definir o VF, principalmente no IC. Em alguns momentos eles são apresentados com o nome de "verbos frasais", em outros como "verbos de duas palavras", "verbos de duas partes" ou, ainda, "expressões" (AEF). Embora não consideremos essencial o conhecimento de nomenclaturas, essa confusão terminológica pode atrapalhar o aluno.

Quanto à prática, predominam exercícios escritos de associação ou preenchimento de lacunas. Há poucas propostas de produção, salvo em alguns exercícios do IC. Este é outro ponto que precisa ser melhorado, porque, é justamente ao produzir que o aluno realmente exercita o que estudou. Esta predominância de exercícios mais "objetivos", que demandam menos tempo para reflexão é, em nossa visão, um reflexo da concepção instrumental de ensino, a qual é marcada por exercícios mecanicistas e pela busca por resultados mais imediatos.

Nos níveis 2, 3 e 4, o AEF apresenta, ao todo, 104 VFs. Porém, há 4 casos de repetições, e, como consequência, o aluno estuda na verdade 100 novos verbos. Não computamos nesta conta os verbos que aparecem em textos e áudios, computamos apenas aqueles ensinados explicitamente, através de tópicos. A quantidade, em si, é satisfatória para ajudar o aluno em muitas de suas necessidades de comunicação. Porém, dentre estes verbos novos, apenas 28 estão no ranking do British National Corpus (BNC) de frequência de VFs. Verbos como carry out, point out, make up, take over, turn up, bring about, que não constam no conteúdo desta série, são exemplos de verbos que enriqueceriam o vocabulário do aluno e aumentariam a gama de situações enunciativas para as quais ele estaria preparado para se comunicar.

Em um balanço final, temos indícios para concluir que LDs que têm grande alcance nas escolas de ensino de inglês fazem uma cobertura de VFs que consideramos fraca, suficiente apenas para capacitar o aluno a formular enunciados mais básicos, mas insuficiente para capacitá-lo a ter uma conversa na qual estruturas mais complexas podem surgir. Logo, há espaço para melhoras como uma definição mais precisa do que é um VF, mais contextualização, mais exercícios de produção e a inclusão de mais verbos do ranking BNC no conteúdo.

Outro problema que observamos foi a forma como os LDs abordam as preposições que constituem os VFs. Observamos que, de modo geral, os LDs têm apenas explorado as noções espaciais destas. Noções de aspecto, tempo, intensidade, finalidade, autoria, posse e várias outras acepções das preposições são pouco exploradas. Além disso, o 
ensino do que ambos os LDs classificam como preposições de lugar resume-se a poucas preposições, praticamente apenas in, on, at e under. Não há nenhuma ocorrência, por exemplo, de off, como em He lives off the coast of Lisbon (Ele mora saindo da costa de Lisboa). A função de on em uma construção como He is on Prozac (Ele está à base de Prozac, tratando-se com Prozac) também não é mencionada, nem a função de up em um enunciado como Drink up! (Bebe tudo logo!). Também não há um exemplo de by, como em He saved a lot of money by doing so (Ele economizou muito dinheiro fazendo isso). Ou ainda, o along em Clap along if you feel like happiness is the truth (Bata palmas se você sentir que a felicidade é a verdade) (WILLIAMS, 2013). Existem várias outras ausências como estas, como demonstra Passarelli (2020) em seu estudo sobre os VFs do inglês, o que corrobora nossa hipótese de que as preposições são cobertas de forma superficial pelos LDs. É possível dizer, em linhas gerais, que os LDs se preocupam, sobretudo, em preparar o aluno para elaborar sentenças básicas como "O banco/cinema/restaurante/ fica na frente de/ao lado/à esquerda da praça/do semáforo/do hospital", entre outras, em seções geralmente denominadas giving directions (explicar onde fica um local). Isto é marcante, sobretudo nos livros da série Interchange (2017).

Além disso, nos enunciados relativos a orientações, a preposição tem um caráter essencialmente estático uma vez que está localizando objetos geralmente imóveis. Porém, na língua, a preposição tem a função de expressar movimento também. No inglês esta função é ainda mais marcante uma vez que verbos como "subir", "descer", "entrar", "sair" e "contornar" são todos formados com o auxílio de preposições, como em go up, go down, get in/into, get out, walk around (subir, descer, entrar, dar a volta em). Dos oito livros analisados, apenas em uma página do IC encontramos algo sobre a função de expressar movimento, com apenas quatro preposições - out, into, around e through.

Além da pouca profundidade da abordagem, novamente observamos equívocos de ordem terminológica que podem confundir o aluno, por exemplo, apresentar locuções como on the corner of e in front of como "preposições". Não existe a preposição "on the corner of" assim como não existe, em português, a preposição "na esquina".

Assim, em vista do que observamos em nossas análises, podemos reafirmar que muitas dificuldades dos alunos com VFs não são resolvidas pelas abordagens adotadas pelos livros didáticos.

\section{Reflexões didáticas com o verbo frasal put off}

Nesta seção, buscamos ilustrar tudo o que foi dito nas seções anteriores através de um exemplo extraído do jornal The New York Times, contendo o verbo frasal put off.

Put off, segundo os dicionários, significa adiar e, de acordo com o British National Corpus (2000), é o $82^{\circ}$ VF mais frequente da língua inglesa. Como vimos na seção anterior, VFs 
como este, quando aparecem, são apresentados em uma lista e, na sequência, praticados através de exercícios de preenchimento de lacunas. Nossa proposta é fazer algo bem mais desafiador, com base nos princípios da TOPE e no conceito de tradução dos quais falamos anteriormente.

Inicialmente, ao invés de uma lista, propomos introduzir o novo VF através de um texto ou, por exemplo, uma manchete de jornal, como esta:

1. The Senate began debate today on a Federal budget that would reduce the deficit by $\$ 52$ billion in 1986, but the Republican leadership put off a symbolic vote on the plan when it appeared it was short of the votes needed to win. (FUERBRINGER, 1982).

(O senado iniciou hoje um debate sobre um orçamento federal que reduziria o déficit em 52 bilhões, mas a liderança republicana adiou uma votação simbólica do plano quando soube que faltavam os votos necessários para vencer). (tradução nossa)

Put é primordialmente conhecido pelos alunos como pôr. Já o outro componente do VF, a preposição off, é mais conhecida dos alunos como desligado(a), por causa da tecla off dos diversos aparelhos eletrônicos. Somando-se as duas leituras teríamos algo como "pôr desligado", que não é bem formado e, obviamente, não é o que o enunciado quer dizer. Portanto, para construir o sentido do VF, o aluno precisará usar seu raciocínio metalinguístico sobre as marcas contextuais e cotextuais do mesmo. Assim, o aluno terá de observar que o contexto da esquerda, de "The Senate... in 1986", apresenta o tema "debate sobre o orçamento" e informa que este orçamento "reduziria o déficit em 52 milhões". A conjunção but, que inicia o contexto da direita, apresenta uma quebra de expectativa. Indica que o restante do enunciado, cujo núcleo predicativo é put off, expressa uma ideia contrária ao tema. Esta ideia é reforçada por "[...] short of the votes needed to win", a qual estabelece uma relação de causa com "put off". Em suma, o aluno é levado a perceber um movimento contrário à realização da votação. Porém, esta não realização da votação é apenas temporária - até que o partido tenha os votos que precisa. Logo, não se trata de um cancelamento, mas de um "adiamento" da votação. Esta reflexão é mais um exemplo da atividade epilinguística da qual falamos anteriormente. Para estimular esta reflexão, podemos usar uma pergunta de caráter geral, como: What does the headline say? (O que diz a manchete?).

Para explorar mais especificamente o VF, podemos aplicar uma pergunta direta como: What does "put off" mean? (O que "put off" significa?) O aluno novamente terá de usar sua metalinguagem inconsciente para responder. Suas representações de put remetem a algo que é "posto" ou "colocado" em algum lugar. Neste caso, é a votação que será colocada, não exatamente em um "lugar", mas em um novo "momento" no futuro. 
Outra possibilidade é pedir que o aluno produza um enunciado com o VF ensinado, como em: Write a sentence with the verb put off (Escreva uma oração com o verbo put off). Para aumentar o grau de dificuldade, o exercício pode ser oral.

A produção também pode ser estimulada através de exercícios de parafraseamento. Porém, ao invés de usarmos equivalentes tradicionais de put off como postpone (adiar), propomos usar marcas menos óbvias para a reformulação do enunciado, por exemplo, a expressão change one's mind (mudar de ideia). Assim, poderíamos pedir: Reescreva a oração dada, usando a expressão "changed one's minds" (Resposta: "The Senate began debate today on a Federal budget that would reduce the deficit by $\$ 52$ billion in 1986, but the Republican leadership changed their minds about a symbolic vote on the plan when it appeared it was short of the votes needed to win). Ou, para manter o foco no trabalho com verbos, podemos usar o verbo leave (deixar), por exemplo, o que nos daria "The Senate began debate today on a Federal budget that would reduce the deficit by $\$ 52$ billion in 1986, but the Republican leadership left the vote for another day when it appeared it was short of the votes needed to win. Esta última paráfrase só é possível porque "deixar um evento para outro dia" faz parte do domínio nocional de /adiar/.

Este exercício torna-se mais desafiador porque articula o sentido à forma, o que é a proposta da vertente enunciativa.

A preposição off, por sua vez, indica desconexão, afastamento. Para que o aluno entenda um VF como put offé preciso que este sentido da preposição seja mais abordado em sala de aula do que é atualmente. Assim, o aluno deve ser exposto a mais ocorrências desta preposição. Observemos alguns exemplos:

2. The machine cut off his finger (A máquina cortou o dedo dele fora) (PASSARELLI, 2020, p. 115)

3. Fernando de Noronha is off the coast of Natal (Fernando de Noronha fica saindo da costa de Natal) (PASSARELLI, 2020, p. 116).

4. Off with you! (Vai embora! / Some!) (The free dictionary, 2019)

5. He took off his jacket because it was getting hot (Ele tirou a jaqueta porque estava ficando quente) (WILD, 2010, p. 87)

6. The plane took off at 19:00 (O avião decolou às 19:00 hs) (PASSARELLI, 2020, p. 135). 
Observamos que, nos cinco exemplos, há um elemento que não varia - a ideia de desconexão, separação. Em 2, o dedo é desconectado do resto da mão; em 3, Fernando de Noronha está desconectada do continente; em 4, o enunciador ordena que seu interlocutor se afaste para outro lugar, que está desconectado do atual; em 5, a camisa é separada do corpo e, em 6, o avião se separa da pista. Desconexão/separação estão, portanto, no centro da Noção /off/. Constituem seu sentido fundamental. No enunciado 1, portanto, a votação é afastada, é "desconectada" do momento atual. É fundamental o aluno perceber este traço de off - separação espacial - para que ele possa assimilar esta preposição em toda sua plenitude de acepções.

Ao contrário de off, que não é abordada diretamente nos LDs analisados, on costuma ser tópico de ensino. Porém, em nossa visão, é ensinada de forma insatisfatória também. Nos oito níveis das séries analisadas, enfocam-se apenas duas acepções desta partícula: 1) com o sentido de "sobre, em cima de", como em The wallet is on the counter (A carteira está em cima do balcão); 2) com o sentido de à/na, nos exercícios de explicações sobre como chegar a algum lugar, como em on the right, on the left, on Mulberry Street (à direita, à esquerda, na rua Mulberry, entre outros). Porém on possui outros sentidos igualmente importantes, um deles é o de indicador de continuidade de uma ação. Trata-se de um valor aspectual presente em incontáveis ocorrências. Observemos duas:

7. We really can"t go on living like this - we"ll have to find a bigger house (Não podemos continuar vivendo assim, temos que encontrar uma casa maior) (Dicionário Cambridge online, 2020)

8. Dream on, dream until your dream come true (Continue sonhando, sonhe até seu sonho se realizar) (TYLER, 1972)

Temos aí mais um exemplo bem claro de como os LDs não capacitam o aluno a lidar com VFs. Eles privilegiam um sentido de on - aquele que, segundo a visão instrumental, é o sentido mais "útil" desta marca - e praticamente ignoram outras acepções da partícula. Não é surpresa, portanto, que existam tão poucos VFs na produção dos alunos.

Ainda sobre off e on, é interessante mencionar a observação de Dufaye (2006) sobre os valores positivos e negativos destas preposições. On, segundo o autor, está ligada à positividade ao passo que off remete a noções de negatividade. Observemos dois exemplos dado pelo autor:

9. Monkeys feed on bananas (Macacos se alimentam de bananas) (DUFAYE, 2006, p. 171) 
10. Pepsi feeds off public ignorance (A Pepsi se alimenta da ignorância do público) (DUFAYE, 2006, p. 171)

11. *Monkeys feed off bananas. (DUFAYE, 2006, p. 171)

12. *Pepsi feeds on public ignorance. (DUFAYE, 2006, p. 171)

*Construção impossível.

Observamos que, embora tanto feed on quanto feed off se traduzam por "alimentar-se de", não podemos usar feed on para algo negativo como a ignorância, uma vez que on está ligada à positividade. Por outro lado, não dizemos feed off bananas porque off remete mais à negatividade. Dicas como essa enriqueceriam consideravelmente o conhecimento do aluno e são uma ótima demonstração do processo de observação minucioso das marcas linguísticas preconizado pela TOPE (CULIOLI, 2000).

As propostas e reflexões apresentadas aqui não representam algum tipo de "revolução" dentro do ensino de LE. Pelo contrário, são propostas simples, porém, em nossa visão, muito enriquecedoras, caso o professor esteja disposto a abrir mão da comodidade de ensinar apenas as estruturas vistas como mais "instrumentais" para o aluno, em favor de um ensino mais amplo e mais reflexivo. É um trabalho árduo, não podemos negar, mas mais frutífero e recompensador também a longo prazo.

\section{Considerações finais}

Tínhamos dois grandes objetivos ao iniciar este artigo: o primeiro era demonstrar que a enunciação, especialmente a TOPE, pode contribuir para o ensino de línguas como uma alternativa às práticas instrumentais. E o segundo, nesse contexto, observar os verbos frasais, seu funcionamento e as dificuldades que esse tópico gramatical coloca para o ensino de língua inglesa. Assim, atendendo ao primeiro objetivo, apresentamos um breve resumo dos tópicos mais pertinentes da teoria de Culioli para nosso trabalho, quais sejam, a atividade epilinguística e a noção. Como a TOPE costuma ser extremamente complexa para quem não é iniciado em seus estudos, buscamos simplificar ao máximo nossa apresentação. Discutimos também o conceito de tradução sob a ótica enunciativa. No último item, através da manchete do The New York Times, pudemos observar como estes conceitos podem incidir sobre o ensino. Vimos que a Atividade Epilinguística (AE) e a noção agem sobre a produção e reconhecimento de formas. A AE é o próprio raciocínio sobre os dados linguísticos. Implica, sobretudo, as reações sensoriais que o aluno tem em relação a signos como /put/, /off/, /republicans/, entre outros (representação), as marcas linguísticas que encontra para expressar sua representação (referência) e as relações com seu(s) interlocutor(es) para construir o sentido (regulação). A noção determina as 
ideias que possuem relação com /put off/ (jogar para longe, afastar, por longe, por mais para a frente, entre outras), são o "cardápio" de opções que o aluno tem para construir o sentido do Verbo Frasal. Se o ensino mais tradicional privilegia as estruturas, a aplicação dos conceitos enunciativos nos proporciona um maior equilíbrio entre o ensino de forma e sentido, estimulando uma prática que permite ao aluno refletir e produzir.

Para atingir nossa segunda meta, propiciar um maior entendimento dos verbos frasais do inglês, primeiramente fizemos uma descrição geral destas marcas para, ao final, analisálas sob a ótica enunciativa. Esta análise nos permitiu sugerir uma proposta de ensino dos VFs. Propiciamos, ainda, uma reflexão sobre como aprimorar as seções que abordam VFs nos livros didáticos.

Finalmente, como última nota, lembramos que o ensino no Brasil possui problemas crônicos que vão muito além da esfera linguística - questões político-administrativas, questões referentes à formação de professores, revisão de currículos, questões motivacionais, entre várias outras, que, infelizmente, não caberiam dentro de um único trabalho (PASSARELLI, 2020).

\section{REFERÊNCIAS}

BENVENISTE, É. Problemas de Linguística Geral / e II. Campinas: Pontes, 1989.

BIASOTTO-HOLMO, M. Uma abordagem culioliana para o fenômeno da tradução. Cadernos de Tradução, Florianópolis, v. 1, n. 25, p. 177-195, set. 2010. Disponível em: https://periodicos.ufsc.br/index.php/traducao/article/view/2175-7968.2010v1n25p177. Acesso em: 21 mar. 2017.

BRITISH NATIONAL CORPUS CONSORTIUM. British national corpus: World edition. Oxford: Humanities Unit of Oxford University, 2000.

BRYSON, B. Troublesome words. 3. ed. Londres: Penguin Books, 2002.

CULIOLI, A. Pour une linguistique de l'enonciation: operations et représentations. Paris: Ophrys, 2000.

CULIOLI, A. Pour une linguistique de l'énonciation: formalisation et opérations de repérage. v. 2. Paris: Ophrys, 1999.

CULIOLI, A. Pour une linguistique de l'énonciation. Paris: Ophrys, 1990. 
CULIOLI, A. Notes du séminaire de D.E.A. 1983-1984. Paris: Poitiers, 1985.

DUFAYE, L. OFF and ON: Projet de représentation formelle. Cycnos, Nice, v. 23, n. 1, 2006.

FRANCKEL, J.-J.; PAILLARD, D. Aspectos da teoria de Antoine Culioli. In: ROMERO, M.; BIASOTTO-HOLMO, M. (org.). Linguagem e enunciação: representação, referenciação e regulação. São Paulo: Contexto, 2011.

FUERBRINGER, J. Action on budget put off by G.O.P.; Dole hunts votes. The New York Times, New York, 1982. Disponível em: https://www.nytimes.com/1985/04/26/us/actionon-budget-put-off-by-gop-dole-hunts-votes.html. Acesso em: 26 abr. 2017.

FUCHS, C. La Paraphrase. Paris: PUF, 1982.

GO ON. In: CAMBRIDGE Dictionary. Cambridge: Cambridge University Press, 1999. Disponível em: https://dictionary.cambridge.org/pt/dicionario/ingles/go-on. Acesso em: 13 mar. 2020.

LATHAM-KOENIG, C.; OXENDEN, C. American English File. Coleção. 2nd edition. Practice. Oxford: Oxford University Press, 2014.

MARCHENA, E.; HULSTJIN, J. H. Avoidance: grammatical or semantic causes? Studies in Second Language Acquisition, Cambridge, v. 11, n. 3, p. 241-255, dez. 1989.

PASSARELLI, J. D. F. O ensino de língua estrangeira sob o viés da teoria das operações predicativas e enunciativas: um estudo dos verbos frasais do inglês. 2020. Tese (Doutorado em Linguística) - Centro de Educação e Ciências Humanas, Universidade Federal de São Carlos, São Carlos, 2020.

REZENDE, L. M. Atividade epilinguística e o ensino de língua portuguesa. Revista do GEL, São Paulo, v. 5, n. 1, p. 95-108, 2008.

RICHARDS, J. C.; HULL, J.; PROCTOR, S. Interchange. Coleção. 5th edition. Cambridge: Cambridge University Press, 2017.

SMABY, R. M. The Structure in Paraphrase Grammars. In: SMABY, R. M. Paraphrase Grammars. Formal Linguistic Series. v. 2. Springer: Dordrecht, 1971.

SMITH, L. P. English idioms: Society for pure English tract XII. Oxford: Clarendon Press, 1923. 
TYLER, S. DREAM ON. 1972. Música. Intérprete: Aerosmith. In: DREAM ON. Boston: Columbia, 1972. 1 disco vinil, faixa única (5 min).

VOGÜÉ, S. de. Culioli após Benveniste: enunciação, linguagem, integração. In: VOGÜÉ, S. de; FRANCKEL, J.-J.; PAILLARD, D. Linguagem e Enunciação - representação, referenciação e regulação. São Paulo: Contexto. 2011.

WILD, C. Attitudes towards English usage in the late modern period: the case of phrasal verbs. 2010. Tese (Pós-doutorado em Filosofia) - Faculdade de Artes, Escola de Estudos Críticos, Universidade de Glasgow, Reino Unido, 2010.

WILLIAMS, P. HAPPY. Música. In: GIRL. Columbia, 2013. 